\title{
PERANCANGAN PROTOTYPE TAMPILAN ANTARMUKA PENGGUNA APLIKASI WEB KAMARDAGANG.COM DENGAN TEKNIK FLAT DESIGN PADA PT. SELARAS UTAMA INTERNASIONAL
}

\author{
Syifa Fauzia ${ }^{1}$, Fenty Eka Muzayyana Agustin ${ }^{2}$ Undang Syaripudin $^{3}$ Yuditha Ichsani $^{4}$ \\ 1, 2,4 Teknik Informatika UIN Syarif Hidayatullah Jakarta \\ ${ }^{3}$ Teknik Informatika UIN Sunan Gunung Djati Bandung \\ ${ }^{1}$ undang_if@uinsgd.ac.id, ${ }^{2}$ fenty.eka@ $@$ uinjkt.ac.id ${ }^{3}$ undang_if@uinsgd.ac.id, \\ 4yuditha.ichsani@uinjkt.ac.id
}

\begin{abstract}
ABSTRAK
Meskipun pertumbuhan e-commerce di Indonesia terbilang pesat namun tidak semua tampilan antarmuka pengguna aplikasi web e-commerce di Indoensia memiliki karakteristik yang user friendly. Padahal setiap user tentu mengharapkan tampilan antarmuka pengguna dengan kategori user experience yang memuaskan terutama dalam bidang e-commerce. Salah satu web e-commerce yang tampilan antarmuka penggunanya masih dibuat sederhana dan belum memenuhi kriteria user friendly yaitu kamardagang.com. Web tersebut milik PT. Selaras Utama Internasional yang menjadi tempat bagi penulis dalam melaksanakan penelitian, dengan melakukan perancangan prototype tampilan antarmuka pengguna terlebih dahulu pada web kamardagang.com tentunya dengan memanfaatkan kelebihan dari Flat Design diharapkan akan memudahkan para front end programmer untuk membangun suatu tampilan antarmuka aplikasi web yang sebenarnya dengan mengaplikasikan desain prototype yang telah dibuat. Di dalam paper ini telah dirancang Prototype Tampilan Antarmuka Pengguna Aplikasi Web Kamardagang.com dengan teknik Flat Design pada PT. Selaras Utama Internasional.
\end{abstract}

Kata Kunci: flat design, user interface, website

\begin{abstract}
Despite the growth of e-commerce in Indonesia is quite fast, but not all of the user interface of web applications of e-commerce in Indonesia has the characteristics of user friendly. In fact, every user will expect to see the user interface with a satisfying user experience category, especially in the field of e-commerce. One of the e-commerce web that its user interface is simple and user friendly yet meet the criteria is kamardagang.com. The site is owned by PT. Selaras Utama Internasional, the place for author in conducting research, by designing the prototype of user interface kamardagang.com on the website, of course, by using the advantages of the Flat Design is expected to facilitate the front end programmer to build a real web application interface by applying the prototype design has been created. In this paper has been designed User Interface Prototype of Kamardagang.com Web Applications with Flat Design technique at PT. Selaras Utama Internasional.
\end{abstract}

Keywords: flat design, antarmuka pengguna, situs web 


\section{PENDAHULUAN}

Nilai estetika atau keindahan menjadi hal utama yang dapat menunjang suatu hasil karya sehingga dapat dinikmati oleh mata, jiwa, perasaan, maupun dengan telinga. Keindahan sangat berkaitan erat dengan segala sesuatu yang mencakup kesatuan (unity), keselarasan (harmony), kesetangkupan (symmetry), keseimbangan (balance), dan perlawanan (contrast) [5]. Segala sesuatu di alam semesta ini memiliki nilai estetika atau nilai keindahan tersendiri, seperti langit, bumi dan seluruh isinya yang merupakan keindahan dari hasil karya seni Maha Suci Allah SWT. Manusia juga turut menerapkan ilmu dalam bidang seni yang diturunkan dari para leluhurnya, contoh yang paling umum seperti memahat, mengukir dan melukis. Sedangkan pada era modern seperti sekarang ini dikenal istilah desain grafis yang difungsikan sebagai media untuk menyalurkan kreatifitas dalam bidang seni dengan memanfaatkan teknologi komputer.

Perkembangan teknologi di era globalisasi seperti sekarang ini semakin pesat, terutama perkembangan teknologi di bidang media informasi salah satunya yaitu internet dimana peran internet menjadi sangat penting dalam kehidupan sehari-hari dan menjadi salah satu media informasi yang paling banyak digunakan.

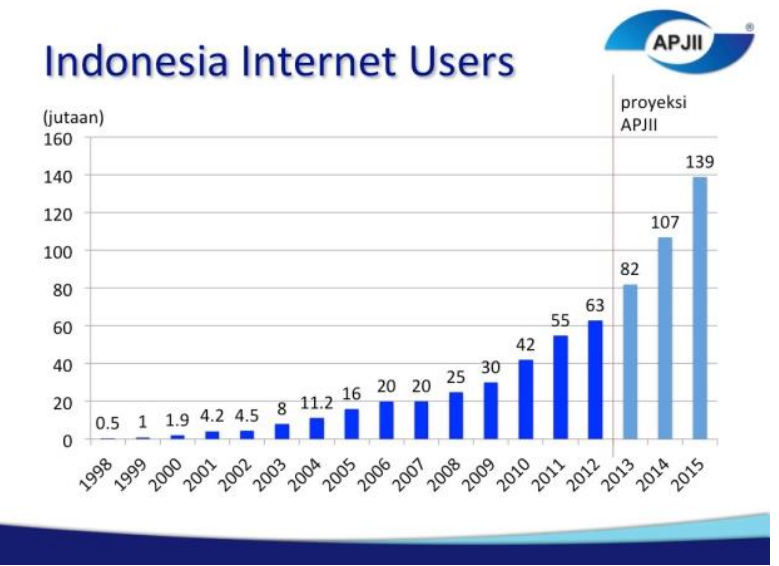

Gambar 1. Grafik Pengguna Internet di Indonesia

(Sumber: [3])

Merujuk pada grafik yang disajikan oleh APJII (Asosiasi Penyelenggara Jasa Internet Indonesia), penggunaan teknologi internet di Indonesia mulai tumbuh semenjak tahun 1998. Di tahun 1998 pengguna internet di Indonesia hanya berjumlah 0.5 juta orang. Kemudian tumbuh pesat hingga menyentuh angka 55 juta pengguna di tahun 2011 dan 139 juta pengguna di tahun 2015 [3]. Pertumbuhan angka penggunaan teknologi internet yang pesat ini memacu pertumbuhan web di Indonesia terutama pada bidang $e$ commerce yang dimanfaatkan untuk memasarkan berbagai macam produk baik barang maupun jasa. Data dari lembaga riset ICD memprediksi bahwa pasar e-commerce di Indonesia akan tumbuh $42 \%$ dari tahun 2012-2015. Angka ini lebih tinggi jika dibandingkan negara lain seperti Malaysia $(14 \%)$, Thailand (22\%), dan Filipina (28\%) [7].

Meskipun pertumbuhan e-commerce di Indonesia terbilang pesat namun tidak semua tampilan antarmuka pengguna aplikasi web e-commerce di Indoensia memiliki karakteristik yang user friendly. Padahal setiap user tentu mengharapkan tampilan antarmuka pengguna dengan kategori user experience yang memuaskan terutama dalam bidang e-commerce. Pendapat ini tentunya diperkuat dengan data yang dikemukakan oleh Google melalui riset mereka yaitu sebanyak $67 \%$ pengguna internet kemungkinan akan melakukan transaksi jika website yang mereka kunjungi adalah website bertampilan user friendly. Sebaliknya, $61 \%$ pengguna akan meninggalkan website dengan desain yang tidak user friendly (Google, 2014), dengan bantuan teknologi komputer yang biasa difungsikan sebagai media desain grafis Flat Design dapat dijadikan alternatif untuk diterapkan pada tampilan antarmuka pengguna aplikasi web agar memiliki karakteristik user friendly. Flat Design dinilai simple dan minimalis sehingga mudah untuk menemukan maksud dari desain yang diberikan [9].

Salah satu web e-commerce yang tampilan antarmuka penggunanya masih dibuat sederhana dan belum memenuhi kriteria user friendly yaitu kamardagang.com. Web tersebut milik PT. Selaras Utama Internasional yang menjadi tempat bagi penulis dalam melaksanakan penelitian, dengan melakukan perancangan prototype tampilan antarmuka pengguna terlebih dahulu pada web kamardagang.com tentunya dengan memanfaatkan kelebihan dari Flat 
Design diharapkan akan memudahkan para front end programmer untuk membangun suatu tampilan antarmuka aplikasi web yang sebenarnya dengan mengaplikasikan desain prototype yang telah dibuat. Tujuan penulisan paper ini adalah merancang Prototype Tampilan Antarmuka Pengguna Aplikasi Web Kamardagang.com dengan Teknik Flat Design pada PT. Selaras Utama Internasional.

\subsection{Aplikasi Web}

\section{TINJAUAN PUSTAKA}

\subsubsection{Definisi Aplikasi Web}

Menurut [10] aplikasi web adalah sebuah sistem informasi yang mendukung interaksi pengguna melalui antarmuka berbasis web. Fitur-fitur aplikasi web biasanya berupa data persistence, mendukung transaksi dan komposisi halaman web dinamis yang dapat dipertimbangkan hibridisasi, antara hipermedia dan sistem informasi. Menurut [4], aplikasi web adalah aplikasi yang mempunyai arsitektur three-tier yang dijalankan pada browser sebagai front end. Menurut [3], aplikasi web atau yang biasa disebut web application ialah suatu website yang membuat pengguna dapat mengakses internet melalui software dari berbagai komputer atau device yang terkoneksi dengan internet.

Berdasarkan ketiga pendapat tersebut, dapat diambil kesimpulan bahwa aplikasi web adalah sistem informasi yang mendukung interaksi pengguna yang dijalankan pada browser sebagai front end dimana penggunanya dapat mengakses internet melalui software dari berbagai komputer atau device yang terkoneksi dengan internet.

\subsubsection{Karakteristik Aplikasi Web}

Aplikasi Web memiliki karakteristikkarakteristik sebagai berikut [10]:

1. Aplikasi Web akan secara konstan meningkat dan informasi yang dimasukan ke dalam dan disajikan oleh situs Web juga akan berubah. Tidak seperti perangkat lunak konvensional yang melalui perencanaan dan revisi terpisah pada waktu tertentu di dalam siklus hidupnya, aplikasi Web secara terus menerus meningkat dalam kaitannya dengan kemampuan dan ketidakstabilan kebutuhan.
2. Aplikasi Web tidak terpisahkan dari perangkat lunak. Konten yang dapat mencakup teks, grafis, citra, audio, dan/atau video terintegrasi dengan pengolahan prosedural.

3. Aplikasi Web bertujuan untuk digunakan secara luas oleh komunitas pengguna yang variable, dengan sejumlah besar pengguna anonim (bisa menjadi jutaan, seperti kasus eBay dan 2000 Sydney Olympics Website) dengan berbagai kebutuhan, harapan, dan sekumpulan keahlian.

4. Saat ini, kebanyakan sistem berbasis Web adalah content-driven (databasedriven). Pengembangan sistem berbasis Web meliputi penciptaan dan manajemen dari konten, seperti halnya ketentuan yang sesuai untuk penciptaan konten dan pemeliharaan.

5. Secara umum, kebanyakan sistem berbasis Web menuntut "look and feel", menyokong kreativitas visual, dan inkorporasi multimedia dalam presentasi dan antarmuka.

6. Aplikasi Web mempunyai jadwal pengembangan yang dipadatkan dan tekanan waktu yang padat.

7. Pencabangan kegagalan atau ketidakpuasan pengguna dari aplikasi berbasis Web sering lebih buruk daripada sistem IT konvensional.

8. Media pengiriman untuk aplikasi Web sangat berbeda dengan perangkat lunak tradisional. Aplikasi Web harus mengatasi berbagai format dan perangkat tampilan, dan mendukung perangkat keras, perangkat lunak, dan jaringan dengan kecepaan akses yang beragam.

9. Keamanan dan privasi pada sistem berbasis Web lebih dituntut dibandingkan dengan yang ada pada perangkat lunak tradisional.

10. Web menunjukan suatu ikatan yang lebih besar antara seni dan ilmu daripada yang secara umum ditemui dalam pengembangan perangkat lunak. 


\subsubsection{Jenis Aplikasi Web}

Ada tiga aplikasi Web yang utama, yaitu [10]:

1. Pelanggan berhadapan dengan aplikasi yang dikenal sebagai situs e-commerce atau B2C yang menggunakan internet. Para pelanggan biasanya dapat memilih produk atau jasa yang dibeli dengan menggunakan kartu belanja (shopping card) dan metode pembayaran (Payment Methods). Contohnya adalah www.amazon.com dan www.ebay.com.

2. Pegawai berhadapan dengan aplikasi yang menggunakan intranet didalam perusahaan. Salah satu contohnya adalah aplikasi laporan akuntansi perusahaan.

3. Aplikasi yang berhadapan dengan pelanggan-penyalur dikenal sebagai situs B2B (Bisnis ke Bisnis) dan menggunakan Ekstranet, perluasan dari Intranet yang mengizinkan perusahaan di sisi luar untuk bekerja di dalam ruang yang terlindungi kata sandi.

\subsubsection{Arsitektur Aplikasi Web}

Ada dua komponen dasar di dalam arsitektur Web, yaitu browser Web dan server Web. Browser Web menawarkan antarmuka grafis untuk pengguna dan bertanggung jawab untuk komunikasi dengan server Web dengan penjelasan sebagai berikut [10]:

1. Pengguna meminta suatu layanan dengan mengklik tautan (link) atau dengan mengetikan sebuah perintah dengan keyboard. Browser Web menangkap perintah tersebut dan menerjemahkannya ke dalam permintaan HTTP.

2. Browser kemudian meneruskan permintaan yang baru saja diciptakan kepada server Web dari penyedia konten. Ketika server menerima sebuah permintaan, permintaan tersebut akan diproses.

3. Ketika pemrosesan dilakukan, server Web kemudian mengirimkan kembali respon tersebut ke browser.

4. Ketika browser menerima respon tersebut, browser menerjemahkannya ke dalam bentuk yang dapat dibaca oleh manusia.

\subsection{Kamardagang.com}

Menurut Baskoro selaku Project Manager di PT. Selaras Utama Internasional, kamardagang.com merupakan produk PT. Selaras Utama Internasional yang sedang dikembangkan dalam beberapa bulan terakhir, di mana produk tersebut merupakan sebuah aplikasi yang menyediakan ruang untuk para pebisnis dalam mengelola informasi dan jaringan bisnisnya secara online. Tujuan dari kamardagang.com yaitu memberikan kemudahan bagi para pengusaha untuk menjalankan kegiatan bisnis dalam bentuk $e$ commerce $\mathrm{B} 2 \mathrm{~B}$ (Business to Business) guna mendorong peningkatan kerjasama bisnis di antara para pengusaha. Kamardagang dibangun dalam aplikasi berbasis web dan mobile.

\subsection{Flat Design \\ 2.3.1. Definisi Flat Design}

Flat Design adalah desain dengan pendekatan minimalis yang menekankan kegunaan, dengan desain yang bersih tanpa ada bevel, bayangan, tekstur, berfokus pada tipografi, warna-warna cerah dan ilustrasi dua dimensi [8].

Menurut [2], flat design adalah genre (aliran) desain UI minimalis, atau bahasa desain yang sedang banyak digunakan oleh user interface grapher (seperti website dan web apps). Flat design mengacu kepada style desain interface yang menghilangkan pilihan stylistic yang memberikan ilusi 3 dimensional (seperti drop shadow, gradient, texture, dan depth) dan fokus terhadap penggunaan elemen minimalis, seperti tipografi dan flat colors (warna datar).

Menurut [1], flat design adalah implementasi dari gaya minimalis dan mengaitkannya dengan The Swiss Style yang terkenal pada tahun 1940-an sampai 1950-an. Dari ketiga pendapat tokoh di atas dapat disimpulkan flat design adalah desain dengan pendekatan minimalis yang mengacu pada penggunaan elemen minimalis, seperti tipografi dan flat colors (warna datar).

\subsubsection{Karakteristik Flat Design}

Berikut adalah karakteristik dari flat design [2]:

1. Warna: Dari segi warna flat design menghindari penggunaan warna yang bermacam-macam. Mengkombinasikan 1-3 warna yang cenderung cerah dan solid.

2. Tanpa Efek: Setiap bentuk yang di buat untuk membentuk susunan layout web tidak menggunakan efek seperti gradasi, emboss, dan efek 3D. 
3. Elemen Sederhana: Seperti bentuk kotak, lingkaran, yang di susun rata berpola.

4. Pemilihan Font: Font yang digunakan cenderung sederhana dan seragam. Tidak menggunakan banyak kombinasi jenis font.

5. Minimalis: Hindari membuat desain yang terkesan realistis.

\section{METODE PENELITIAN}

\subsection{Gambaran Umum Perancangan}

Tampilan antarmuka aplikasi web kamardagang.com terdiri dari beberapa menu yang dapat diakses oleh user, diantaranya: menu Sign Up, Sign In, Download, Contact, Language, Search, Add New Business, dan Sign Out. Menu Sign Up digunakan untuk menjadi user dengan status member dari web kamardagang.com dengan mengisikan form yang telah disediakan di web kamardagang.com. Menu Sign In digunakan oleh user yang sudah berstatus member agar dapat mengakses semua menu user di web kamardagang.com. Menu Download menampilkan pop up untuk mengunduh aplikasi kamardagang.com versi mobile. Menu Contact menampilkan pop up beberapa media sosial dan email kamardagang.com. Menu Language memberikan bantuan pengaturan bahasa pada aplikasi web kamardagang.com dimana tersedia dua bahasa yaitu Indonesia dan Inggris. Hasil pencarian dari Search yaitu menampilkan portofolio singkat dari banyak perusahaan dimana dari tiap perusahaan tersebut memiliki jenis produk bisnisnya tersendiri. Adapun menu Add New Business hanya dapat diakses apabila user sudah melakukan Sign In, halaman tersebut berfungsi untuk menampilkan bisnis yang diinput user pada halaman hasil pencarian dari Search yaitu Search Result Page.

\subsection{Tujuan Perancangan}

Perancangan prototype untuk tampilan antarmuka aplikasi web kamardagang.com ditujukan untuk memudahkan para front end programmer dalam membangun tampilan atarmuka aplikasi web kamardagang.com dimana nantinya front end programmer hanya perlu menerapkan desain prototype yang telah dibuat pada aplikasi web kamardagang.com. Sesuai dengan tugas front end programmer yaitu membangun tampilan antarmuka aplikasi yang dapat dikategorikan user friendly agar user mudah mendapatkan informasi yang dibutuhkan, tool-tips yang informatif, dan slide banner promosi yang efektif karena front end programmer bekerja bukan dengan tuntutan supaya web terlihat bagus dan artistik secara visual melainkan lebih ke sisi fungsionalnya oleh sebab itu dibutuhkan gambaran konten website untuk memudahkan para front end programmer dalam proses building.

\subsection{Syarat-syarat Perancangan}

Kelengkapan yang digunakan untuk perancangan prototype tampilan antarmuka aplikasi web kamardagang.com yaitu sebagai berikut:

Software:

a. Windows 8

b. Adobe Photoshop CS6

c. CorelDRAW X7

d. Google Chrome

Hardware

a. Laptop Asus tipe $\mathrm{A} 45 \mathrm{CB}$

b. RAM 4 GB

c. Processor Intel Core i3-3217U, $1.80 \mathrm{GHz}$

d. Graphics NVDIA GT 740M

\section{HASIL DAN PEMBAHASAN}

4.1. Perancangan Prototype Tampilan Antarmuka Pengguna

Penulis yang berperan sebagai designer membuat logo dan menentukan gaya desain dari tampilan antarmuka aplikasi web kamardagang.com dimana logo dan tampilan antarmuka yang dibuat lebih condong ke arah Flat Design dengan padanan beberapa warna yang cerah serta pengaplikasian beberapa bentuk objek solid seperti persegi dan lingkaran. Setelah menentukan gaya desain, penulis membuat model-model konten yang diatur tata letaknya. Model-model konten tersebut dibuat dengan menggunakan CorelDRAW X7. Selanjutnya dilakukan pengukuran porsi ukuran model. Yang terakhir, adalah pemberian warna dan cropping menggunakan Adobe Photoshop CS6.

Berikut adalah hasil perancangan prototype tampilan antarmuka aplikasi web kamardagang.com

1. Logo

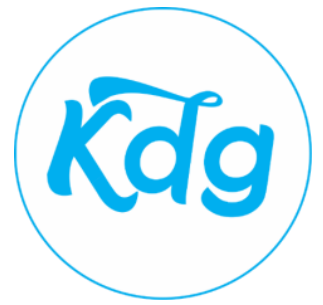

Gambar 2. Prototype Logo Kamardagang.com 
Penulis memilih bentuk lingkaran untuk dasar logo dari web kamardagang.com karena ligkaran merupakan elemen yang sangat populer dalam desain logo. Bentuk lingkaran sangat cocok dengan perusahaan yang ingin memberikan kesan yang dinamis, rotasi, tidak terputus, tidak memiliki awal atau akhir, abadi, dan bersifat menjaga hal-hal yang ada di dalam serta menunjukkan suatu komunitas. Tiga huruf yang terdapat pada logo kamardagang.com yaitu 'Kdg' yang merupakan kependekan dari kamardagang. Penulis menyesuaikan dengan permintaan dari pemilik produk yang menginginkan logonya hanya diwakilkan dengan tiga huruf yaitu 'Kdg' dan dibuat dengan teknik tipografi. Warna biru dan putih menjadi padanan warna untuk logo kamardagang.com. Penulis tidak mengaplikasikan banyak warna pada logo kamardagang karena penulis menginginkan suatu logo yang simple dan mudah diingat.

\section{Home}

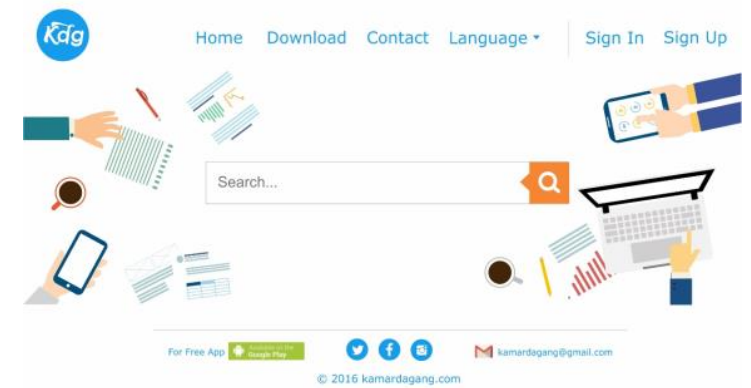

Gambar 3. Prototype Design 1 Home

Kamardagang.com

Penulis membuat tiga desain untuk halaman Home dimana untuk desain pertama penulis mengaplikasikan konten flat desain yang sangat dominan dan objek-objek yang mengisi landing page pada halaman Home cukup mencirikan tema business namun objek-objek tersebut terlalu banyak menggunakan padanan warna sehingga kurang memiliki kesan mature untuk para B2B user.

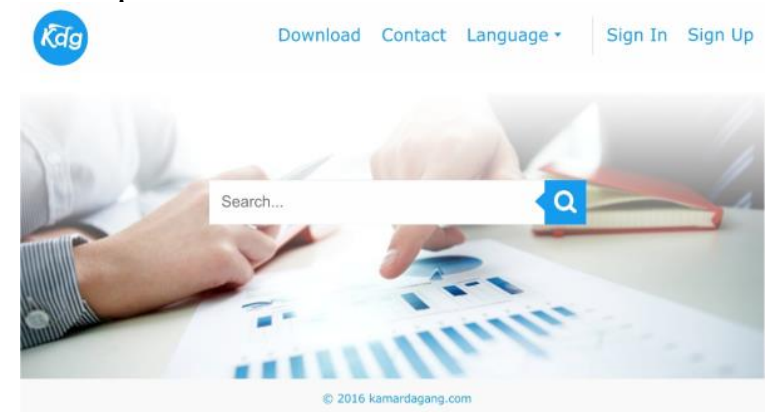

Gambar 4. Prototype Design 2 Home

Kamardagang.com

Pada desain halaman Home yang kedua, penulis menghilangkan objek-objek yang mengisi landing page. Sesuai fungsi dari web kamardagang.com yaitu untuk menjalankan kegiatan business to business maka penulis mengaplikasikan sebuah gambar dengan tema business yang sangat menonjol pada landing page serta menerapkan sedikit efek blur pada header sesuai dengan permintaan dari CEO kamardagang.com.

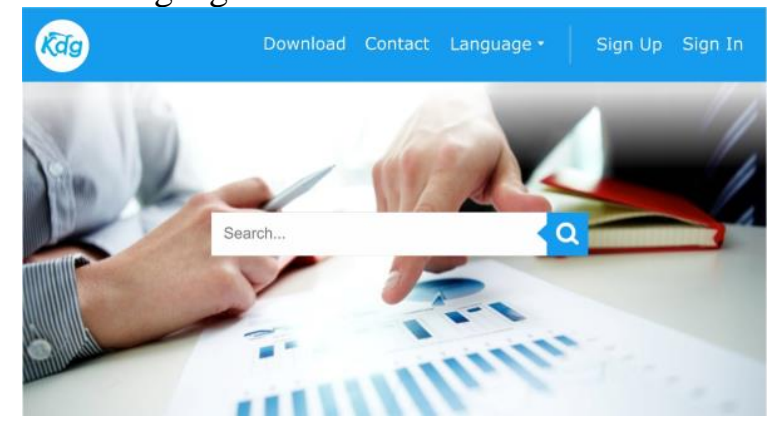

Gambar 5. Prototype Design 3 Home

Kamardagang.com

Desain halaman Home yang ketiga merupakan desain yang diterapkan sebagai interface sebenarnya pada aplikasi web kamardagang.com. Penulis mengganti header menjadi bentuk persegi yang memanjang karena penerapan efek blur membuat header keluar dari karakteristik flat design, karena pada dasarnya flat design hanya mengaplikasikan objek dan warna yang solid. Fungsi halaman Home dapat diakses dengan meng-klik gambar logo kamardagang di pojok kiri.

\section{Header}

खdg Download Contact Language - sign up sign in
Gambar 6. Prototype Header
Kamardagang.com

Bagian header dibuat memanjang penuh kesamping seperti tampilan header web pada umumnya. Warna biru dipilih menjadi warna dasar pada header dengan warna font putih agar selaras dengan warna logo dari web kamardagang.com.

\section{Search Box}

$$
\text { Search... }
$$

Gambar 7. Prototype Search Box Kamardagang.com 
Search box sengaja penulis buat dengan ukuran besar yang diposisikan di tengah gambar dasar dari landing page. Search button pada search box penulis buat terkesan minimalis agar lebih menguatkan karakteristik dari flat design.

\section{Sign Up}

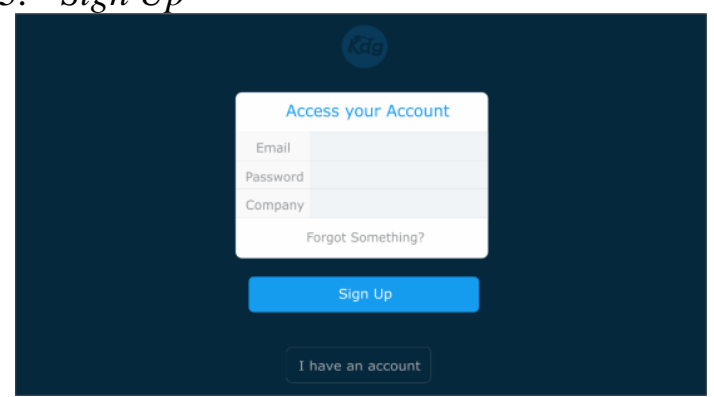

Gambar 8. Prototype Halaman Sign Up

Kamardagang.com

Logo kamardagang.com yang terdapat pada form Sign $U p$ penulis buat terkesan transparent dengan memanfaatkan permainan opacity. Penulis mengaplikasikan warna biru donker sebagai warna dasar pada halaman Sign $U p$ karena penulis ingin membuat ciri khas pada halaman-halaman yang difungsikan sebagai input data dari user. Warna biru yang menjadi ciri khas web kamardagang.com tidak dihilangkan tetapi hanya diaplikasikan sedikit.

\section{Sign In}

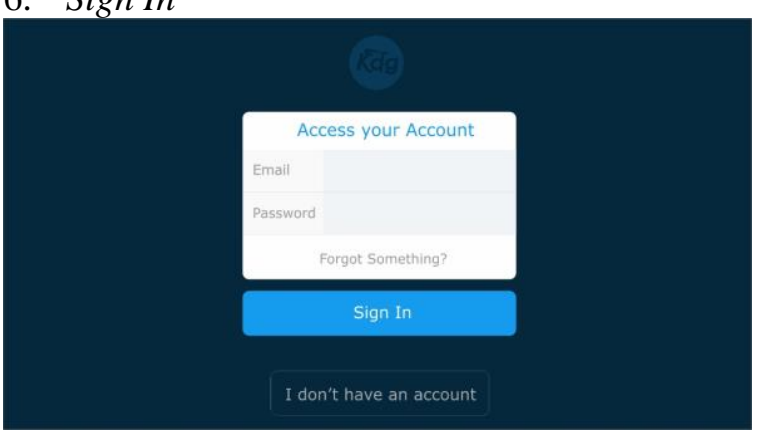

Gambar 9. Prototype Halaman Sign In Kamardagang.com

Desain dari form Sign In tidak berbeda dari form Sign Up yang membedakan hanya konten yang perlu diisi oleh user.

\section{Download}

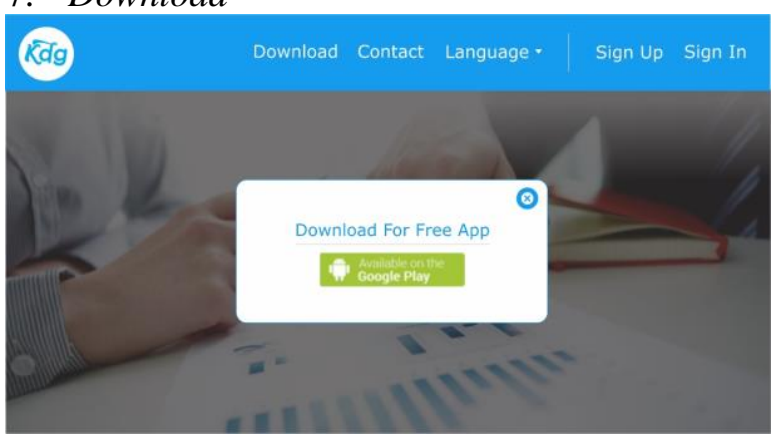

Gambar 10. Prototype Download

Kamardagang.com

Menampilkan pop up yang berfungsi untuk men-download aplikasi kamardagang.com untuk android mobile. Warna dasar pop up lebih dominan ke warna putih dengan sedikit padanan warna biru dengan menggunakan shape persegi panjang dan lingkaran untuk close button. Shape dengan bentuk sederhana dipilih karena sesuai dengan karakteristik dari flat design. Landing page tetap ditampilkan namun dengan tambahan tools opacity sehingga terkesan transparan.

\section{Contact}

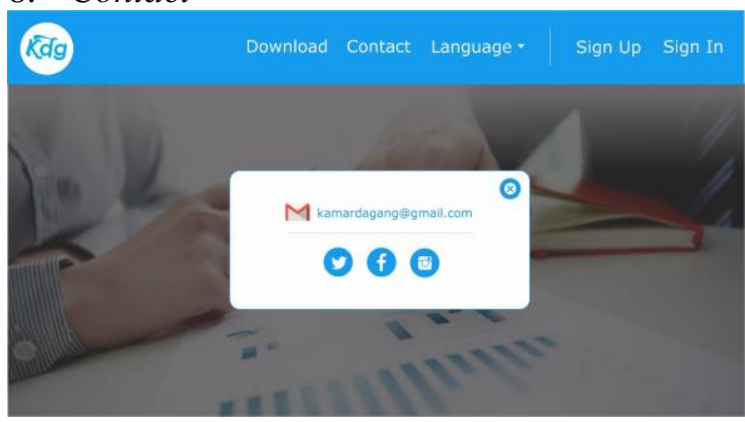

Gambar 11. Prototype Contact

Kamardagang.com

Menampilkan pop up yang berfungsi untuk melihat email dan media social seperti twitter, facebook, dan instagram dari kamardagang.com. Warna dasar pop up lebih dominan ke warna putih dengan sedikit padanan warna biru dengan menggunakan shape yang persegi panjang dan lingkaran untuk close button. Shape dengan bentuk sederhana dipilih karena sesuai dengan karakteristik dari flat design. Landing page tetap ditampilkan namun dengan tambahan tools opacity sehingga terkesan transparan. 


\section{Language}

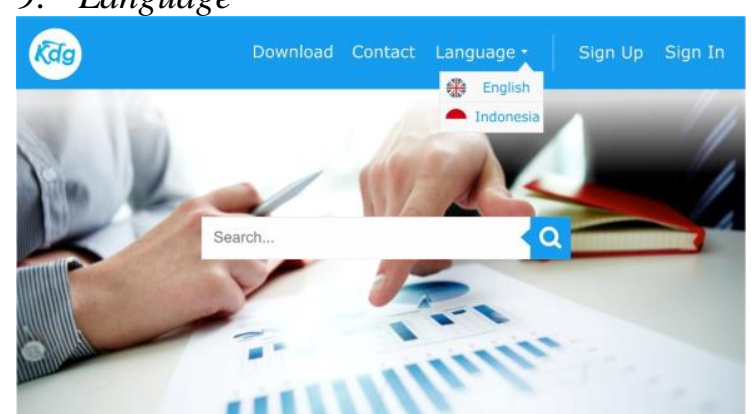

Gambar 12. Prototype Language

Kamardagang.com

Menampilkan pop up yang difungsikan untuk pengaturan bahasa pada web kamardagang.com. Terdapat dua pilihan bahasa yaitu Indonesia dan Inggris. Warna dasar pop up yaitu putih dengan ciri khas warna biru dari kamardagang.com untuk fontnya. Landing page tetap ditampilkan namun dengan tambahan tools opacity sehingga terkesan transparan.

\section{Search Results Page}

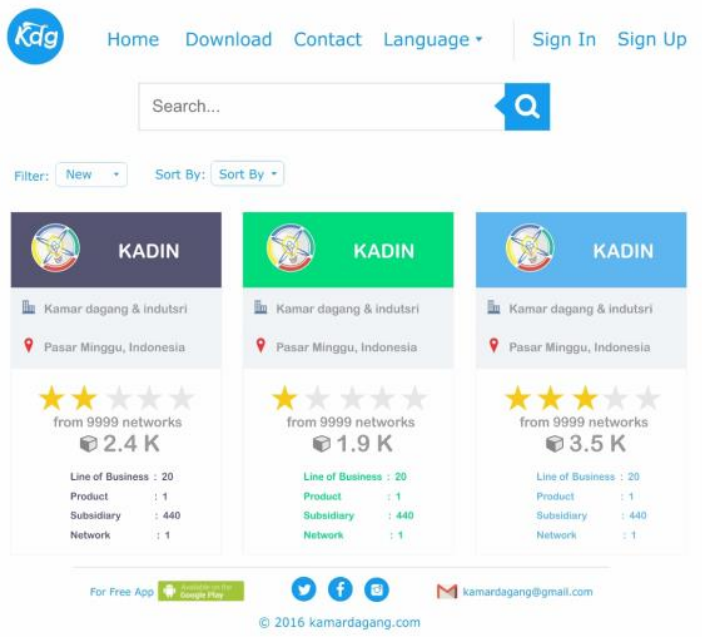

Gambar 13. Prototype Design 1 Search Results Page Kamardagang.com

Search Results Page merupakan tampilan hasil dari pencarian melalui search box yang menampilkan portofolio singkat dari banyak perusahaan dan masing-masing produknya yang disuguhkan dalam bentuk list. Search Results Page dilengkapi dengan tools filter dan sort by yang difungsikan untuk mempermudah pencarian. Penulis membuat dua desain untuk halaman Search Results Page dimana pada desain pertama terdapat list portofolio dengan bar terpisah dan padanan warna yang sedikit berbeda dari tiap bar yang menurut pendapat dari CEO kamardagang.com tampilan bar secara terpisah sangat jarang diterapkan pada aplikasi web sehingga desain tersebut lebih cocok untuk diterapkan pada aplikasi mobile dan pengaplikasian macammacam warna pada tiap bar akan memberikan efek kontras pada konten logo atau gambar dari tiap perusahaan, mengingat logo atau gambar dari tiap perusahaan memliki padanan warna yang bermacam-macam.

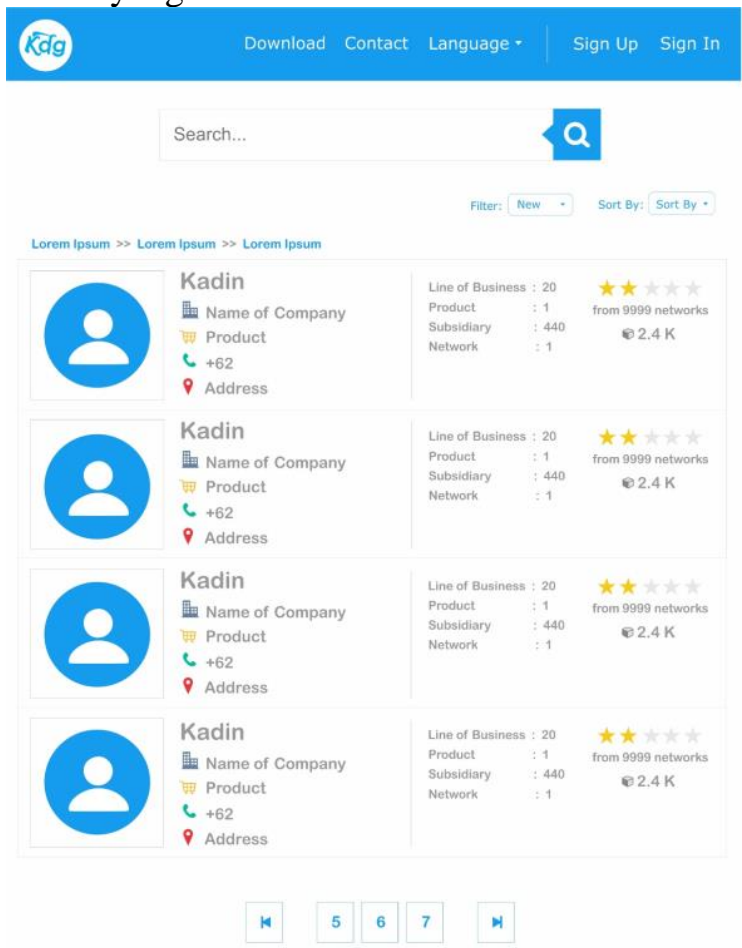

Gambar 14. Prototype Design 2 Search Results Page Kamardagang.com

Penulis mengganti tampilan list dengan bar terpisah menjadi tampilan list yang memuat berbagai macam portofolio dari tiap perusahaan dalam satu bar sekaligus, untuk segi warna didominasi oleh warna dasar putih agar terkesan netral dan dapat memberikan tekanan pada warna-warna lainnya terutama pada logo atau gambar produk dari tiap perusahaan.

\section{Add New Business}

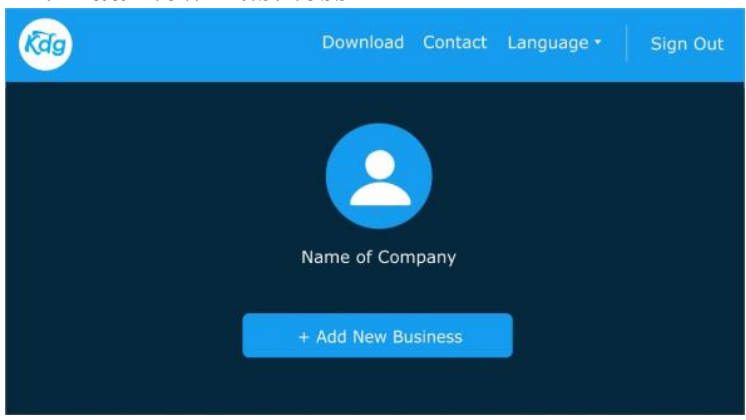


Gambar 15. Prototype Add New Business Kamardagang.com

Halaman ini merupakan halaman yang hanya dapat diakses oleh user yang sudah melakukan Sign Up. Sama seperti halaman Sign In dan Sign $U p$ penulis mengaplikasikan warna ciri khas untuk halaman input data oleh user yaitu biru donker.

\section{Form Add New Business}

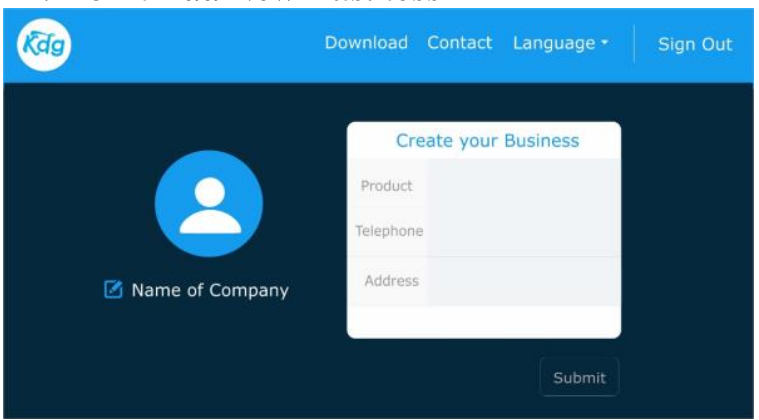

Gambar 16. Prototype Form Add New

Business Kamardagang.com

Halaman ini merupakan halaman lanjutan dari halaman sebelumnya yang difungsikan untuk melakukan submit produk yang nantinya akan ditampilan di halaman Search Result Page. Sama seperti halaman sebelumnya, karena halaman ini merupakan halaman yang difungsikan untuk input data user maka penulis mengaplikasikan warna dasar biru donker namun tetap dengan padanan warna biru yang mencirikan web kamardagang.com.

\subsection{Kesimpulan}

\section{KESIMPULAN}

Dari hasil analisa dan pembahasan yang telah penulis uraikan di atas, dapat disimpulkan bahwa Prototype Tampilan Antarmuka Aplikasi Web Kamrdagang.com mempermudah tugas front end programmer dalam membangun aplikasi web kamardagang.com agar tampilan antarmuka web lebih terstruktur dan tidak menyimpang dari tujuan awal.

\subsection{Saran}

1. Pengembangan lebih lanjut dapat dilakukan untuk hasil yang lebih baik, oleh karena itu penulis menyarankan beberapa hal yaitu sebagai berikut:

2. Rancangan tampilan antarmuka pengguna cakupannya dapat diperluas untuk keseluruhan aplikasi web kamardagang.com untuk bisa mengatur keselarasan tampilan;

3. Rancangan tampilan tidak hanya sebatas gambaran grafis saja tetapi sudah bisa diimplementasikan dalam aplikasi, seperti penggunaan CSS dan javascript.

\section{DAFTAR PUSTAKA}

[1] Anindita, M. Riyanti, MT. 2016 Tren Flat Design dalam Desain Komunikasi Visual. Jurnal Dimensi DKV, Vol. 1-No. 1. April 2016

[2] Argiacyber. 2013. Karakteristik Flat Design.

http://argiacyber.blogdetik.com/2013/12/0 4/karakteristik-flat-desain.

[3] Asosiasi Penyelenggara Jasa Internet Indonesia (APJII). Grafik Pengguna Internet di Indonesia. http://www.apjii.or.id/v2/index.php/read/p age/halaman-data/9/statistik.html (Diakses 5 Desember 2016 pukul 14.17 WIB).

[4] Chan, VN. 2012Aplikasi Berbasis Web untuk Pengendali Pengiriman Gas PT Surya Biru Murni Acetylene Balikpapan. TesisUPN "Veteran" Yogyakarta

[5] Irawan, B. 2013. Dasar-dasar Desain. Bogor: Griya Kreasi.

[6] Irwansyah, E. Moniaga, JV. 2014 Pengantar Teknologi Informasi. Yogyakarta: deePublish.

[7] Mahatma, R. 2016. Data Statistik Mengenai Pertumbuhan Pangsa Pasar ECommerce di Indonesia Saat Ini. https://buattokoonline.id/data-statistikmengenai-pertumbuhan-pangsa-pasar-ecommerce-di-indonesia-saat-ini/

[8] Editorial Team. 2014. Apa itu Flat Design. http://www.pindexain.com/apaitu-flat-design/

[9] Pratas, Antonio. 2014. Creating Flat Design Websites. Birmingham: Packt.

[10] Simarmata, Janner. 2012. Rekayasa Web. Yogyakarta: ANDI. 
